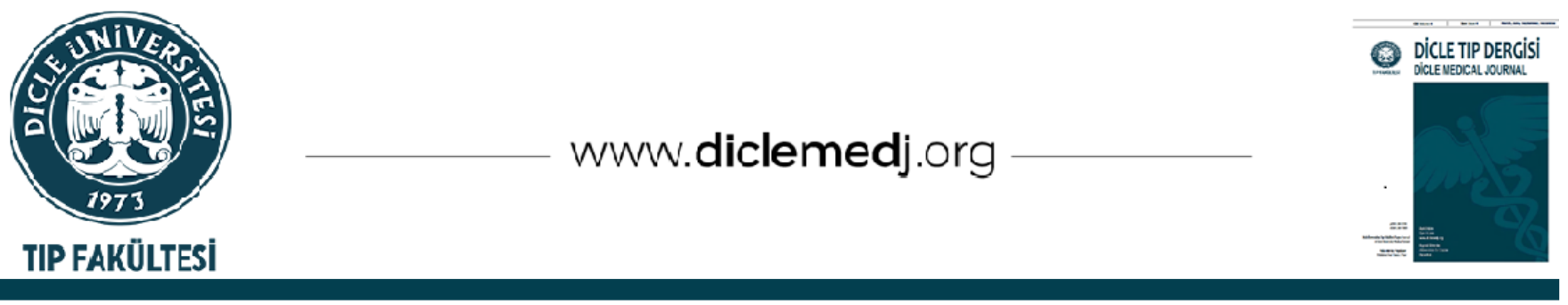

\title{
Otonom Disfonksiyon Parameterleri ile Efor Testi Sırasında İzlenen Ventriküler Erken Vuru Sıklığı ve İskemik ST-segment Değişikliği Varlığı Arasındaki İlişki
}

\author{
Münevver Sarı iD 1, Özlem Karakurt iD 2 \\ 1 Sağlık Bilimleri Üniversitesi, İstanbul Kartal Koşuyolu Yüksek İhtisas Eğitim ve Araștırma Hastanesi, Kardiyoloji Kliniği, İstanbul, Türkiye \\ 2 Sağlık Bilimleri Üniversitesi, Bursa Yüksek İhtisas Eğitim ve Araştırma Hastanesi, kardiyoloji Kliniği, İstanbul, Türkiye
}

Geliş: 24.07.2021; Revizyon: 24.08.2021; Kabul Tarihi: 24.08.2021

Öz

Giriş-amaç: Vagal reaktivasyon normal olarak egzersiz sonrası toparlanmanın erken döneminde meydana gelir. Normal vagal reaktivasyonun yokluğunda, kalp hızı toparlanması (HRR) zayıflar. Kalp hızı türbülansı (HRT), ventriküler ektopiden sonra arteriyel kan basıncındaki bozulmalara verilen otonomik yanıtın bir göstergesidir. HRR ve HRT'nin (türbülans bașlangıcı (TO) ve türbülans eğimi (TS)) prognostik rolü iyi bilinmektedir. Bu çalışmada, egzersiz testi sırasında ventriküler ektopi sıklığı ve iskemik ST-segment değişikliği varlığı ile bu parametreler arasında bir ilişki olup olmadığını araștırmayı amaçladık.

Yöntemler: Koroner arter hastalı̆̆ı ya da kalp yetmezliği olmayan 1550 hastadan 100'ünde (\%6,4) ezgersiz sonrası toparlanma sırasında ventriküler ektopi vardı. Bu hastalarda ventriküler ektopi sıklığı, egzersiz sonrası 1. dakikadaki HRR indeksi, TO ve TS değerlerini ölçtük.

Bulgular: Hastaların \%35'inde T0, \%17'sinde TS ve \%10'unda HRR anormaldi ve TO daha önce bozulmuştu. Hastalar iskemik ST-segment değişikliklerine göre (negatif ve pozitif) gruplandırıldığında; yaş, maksimum METs, egzersiz süresi, TO, TS, TS normal/anormal, HRR, HRR normal/anormal, egzersiz veya toparlanma sırasında ventriküler ektopi sayısı, maksimum kalp hızı ve bazal kalp hızı gruplar arasında benzerdi. Egzersiz testi pozitif olanlarda TO anormal olma eğilimindeydi (p=0.07). HRR ile TS arasında hafif derecede anlamlı bir korelasyon gözlendi ( $r=0.21, p=0.036)$. Toparlanma sürecindeki ventriküler ektopi sayısı, egzersiz sırasındaki ventriküler ektopi sayısı ile korele idi. Ayrıca TS, kalp hızı TO ve HRR ile koreleydi.

Sonuç: Düşük-orta riskli bireylerde, toparlanmanın 1. dakikasındaki HRR ve HRT'nin, otonomik fonksiyonun farklı yönlerini yansıtıyor olabilirler ve bunlar, egzersiz testi sırasındaki iskemik ST-segment değişikliği varlığı ve ventriküler ektopi sıklığı ile ilişkili değildi.

Anahtar kelimeler: kalp hızı toparlanma indeksi, kalp hızı türbülansı, iskemi, prematüre ventriküler kompleks.

DOI: $10.5798 /$ dicletip.988086

Correspondence / Yazışma Adresi: Münevver Sarı, Sağlık Bilimleri Üniversitesi, İstanbul Kartal Koşuyolu Yüksek İhtisas Eğitim ve Araştırma Hastanesi, Kardiyoloji Kliniği, İstanbul, Türkiye e-mail: benmsr@hotmail.com 


\title{
The Relationship between Autonomic Dysfunction Parameters and Ventricular Premature Complex Frequency and Presence of ischemic ST-segment Changes during Treadmill Exercise Test
}

\begin{abstract}
Objectives: Vagal reactivation normally occurs in the early period of recovery, immediately after exercise. In the absence of normal vagal reactivation, heart-rate recovery (HRR) is attenuated. Heart rate turbulence (HRT) is an indicator of autonomic response to perturbations of arterial blood pressure after ventricular ectopy. The prognostic role of HRR and HRT (turbulence onset (TO) and turbulence slope (TS)) is well established. In this study, we aimed to investigate whether there is a relationship between these parameters and frequency of ventricular ectopies and ischemic ST-segment changes during exercise test.
\end{abstract}

Methods: Of the 1550 patients without coronary artery disease or heart failure, 100 (6.4\%) had ventricular ectopia during recovery from exercise. In these patients, we measured the frequency of ventricular ectopia during exercise and recovery, heart rate recovery index at first minute after exercise, TO and TS values.

Results: TO was abnormal in 35\% of patients, TS in $17 \%$ and HRR in $10 \%$, and that TO was impaired earlier. When the patients were grouped according to ischemic ST-segment changes (negative and positive); age, maximum METs, duration of exercise, TO, TS, TS normal/abnormal, HRR, HRR normal/abnormal, number of ventricular ectopies during exercise or recovery, maximum heart rate and basal heart rate were similar between groups. Abnormal TO rate tended to be higher in those with positive exercise test. A mildly significant correlation was observed between HRR and TS ( $\mathrm{r}=0.21$, $\mathrm{p}=0.036)$. The number of ventricular ectopies in the recovery was correlated with the number of ventricular ectopies during exercise. TS was correlated with TO and HRR.

Conclusion: In low-intermediate risk individuals, HRR at first minute of recovery and HRT may reflect different aspects of autonomic dysfunction and they were not associated with presence of ischemic ST-segment changes and frequency of ventricular ectopies during exercise test.

Keywords: heart rate recovery, heart rate turbulence, ischemia, premature ventricular complex.

\section{Giriş}

Egzersiz stres testi, klinik olarak düşük-orta olasılıklı hastalarda koroner arter hastalığı (KAH) tanısında ve risk değerlendirmesinde kullanılır. Egzersiz stres testi, egzersiz süresince ve hemen egzersiz sonrası toparlanma döneminde hastanın semptomunun objektif olarak değerlendirilmesini sağlar ve fonksiyonel kapasite, egzersize kalp hızı ve kan basıncı yanıtı ile elektrokardiyografik STsegment değişiklikleri hakkında bilgi verir ${ }^{1-2}$. Egzersiz testi sırasında ortaya çıkan ventriküler ektopik atımların klinik önemi net değildir. Egzersizle ortaya çıkan ventriküler ektopiler, KAH ve kardiyovasküler mortalite ile ilișkili bulunmuş, diğer taraftan bazı araştırmalarda ilişki olmadığı bildirilmiștiri-2. Egzersizden sonra toparlanma dönemindeki ventriküler ektopiler için en çok suçlanan mekanizma, düşük vagal reaktivasyondur ${ }^{2}$. Vagal reaktivasyonun ventriküler ektopileri baskıladığı bilinmektedir. Kardiyovasküler olay ve ölüm riski sınıflandırması için otonom disfonksiyon ile ilişkili birçok egzersiz testi parametresi araştırılmıştır ${ }^{3}$.

Egzersiz sirasında sempatik sistem aktivasyonu ile maksimum kalp hızına ulaşılırken, egzersizden hemen sonra toparlanmanın erken döneminde vagal reaktivasyon ve sempatik aktivitenin azalması ile kalp hızı ve kan basıncının nerdeyse bazal değerlere dönmesi beklenir. Azalmış vagal tonus ve sempatik hiperaktivite hemodinamik stresi arttırır ve endotel disfonksiyonu, koroner arter spasmı, sol ventrikül hipertrofisi, ciddi aritmiler, inme ve kardiyak nedenli mortalite gelişimine neden olabilir ${ }^{4}$ İstirahatin erken dönemindeki (0.5-2 dakika) azalmada vagal reaktivasyon daha ön 
planda iken, geç dönemdeki azalmada sempatik aktivasyonunun geri çekilmesi etkilidir ${ }^{4}$. Azalmış vagal reaktivasyon varlığında, HRR'de azalma, diğer bir deyişle kalp hızındaki düşüşte gecikme ortaya çıkar. Kalp hızı toparlanma indeksindeki (HRR) ve egzersize verilen anormal kronotropik yanıt, tüm nedenlere bağlı ölüm ve kardiyak olaylarla ilișkili bulunmuştur ${ }^{5-14}$. Bunun iskemi ya da aritmik olaylarla mı ilişkili olduğu net değildir. Bazı çalışmalarda, bu etkinin Duke treadmill skoru ve altta yatan KAH ciddiyetinden bağımsız olduğu gösterilmiștir5,11-14. Kalp hızı türbülansı (HRT), bir prematüre ventriküler komplekten (PVC) sonra arteriyel kan basincindaki bozulmalara verilen otonomik yanıtın bir ölçüsüdür15,16. Kalp hızı türbülansının, mortalite ve aritmik olayların güçlü bir belirleyicisi olduğu gösterilmiştir ${ }^{17,18} . \mathrm{Bu}$ araştırmada, otonomik dengesizlik ile ilgili bu parametreler ile (HRR ve HRT) ile günlük pratikte sıkça kullanılan egzersiz stres testinde, egzersiz sirasinda ve hemen ardindan toparlanma dönemindeki ventriküler ektopi sıklığı ve iskemik ST-segment değişikliği varlığı arasında bir ilişki olup olmadığını araştırmayı amaçladık.

\section{YÖNTEMLER}

Daha önceden bilinen KAH ve kalp yetmezliği olmayan ve egzersiz efor testi yapilan 1550 hasta geriye dönük olarak incelendi. Bu çalışma, Helsinki bildigesindeki etik yönergeler dikkate alınarak yapılmıştır. Bu çalışma hastanemiz etik kurulu tarafından onaylanmıştır (karar no: 2021/7/502). Bu hastaların 100'ünde $(\% 6,4)$ egzersizden hemen sonra toparlanma döneminde ventriküler ektopi vardı. Egzersizden hemen sonra toparlanma döneminde PVC olmayan, 30 yaşından küçük, kalp yetmezliği, digoksin veya antiaritmik ilaç kullanımı olan, betabloker kullanan, orta-ileri derecede kapak hastalığı, son dönem böbrek hastalığı, kalp pili varlığı, kalp nakli öyküsü, atriyal fibrilasyon, kalp bloğu ve istirahatte sık ventriküler ektopi olan hastalar çalıșmaya dahil edilmedi.

Hastalara, modifiye Bruce protokolü kullanılarak semptomla sinırlı egzersiz stres testi uyguland, maksimum eforla egzersiz yapıldı ve egzersizden sonra soğuma yürüyüşü yapılmadan sırtüstü pozisyona alındı. Egzersiz kapasitesi, koşu bandı hızı ve derecesinden ve egzersiz süresinden metabolik eşdeğerler (METs) ile değerlendirildi ve 12 derivasyonlu elektrokardiyografi verileri kaydedildi. Anormal bir ST-segmenti yanıtı, J kavşağında görsel olarak ölçülen $1 \mathrm{~mm}$ veya daha fazla horizontal veya aşağı eğimli ST-segment çökmesi olarak tanımlandı. Egzersize kronotropik yanıt, maksimum egzersizde kullanılan kalp hızı rezervinin [ulaşılabilir maksimum kalp hızı (220-yaş) ile istirahat kalp hızı arasındaki fark] yüzdesi olarak tanımlandı. Kalp hızı rezervinin yüzde 80'inine ulaşılamamış olması, yetersiz kronotropik yanıt olarak kabul edildi. Anormal bir HRR, egzersizden sonraki ilk dakika boyunca kalp hızının 12 vuruștan fazla düşmemesi olarak tanımlandı. Kalp hızı türbülans parametreleri, Schmidt ve ark. tarafından bildirilen orijinal yönteme göre hesapland1 ${ }^{15}$. İki sayısal tanımlayıcı değer ile tanımlandı: sinüs ritmi hızlanmasının ilk aşamasını yansıtan türbülans başlangıcı (turbulence onset, T0) ve kalp hızı yavaşlama aşamasını tanımlayan türbülans eğimi (turbulence slope, TS). Kalp hızı TO, bir PVC'den sonra kompanzatuar duraklamayı izleyen ilk iki sinüs ritmi RR aralığının ortalaması ile PVC'den önceki son iki sinüs ritmi RR aralığının ortalaması arasındaki farkın PVC öncesindeki değere oranının yüzdesi olarak tanımlandı. Kalp hızı TS ise, PVC'den sonraki ilk 20 sinüs ritim aralığı içindeki beş ardışık sinüs ritmi RR aralığının herhangi bir dizisi üzerinden değerlendirilen bir regresyon çizgisinin maksimum pozitif eğimi olarak tanımlandı ve milisaniye/atım olarak ifade edildi. Bir PVC'den sonra birkaç atım güçlü sinüs hızlanmasının 
ardından hızlı bir yavașlama, sağlıklı bir yanıta işaret eder. Böylece, TO $\geq \% 0$ (negatif olması sinüs hızlanmasını ve pozitif olması sinüs yavaşlamasını ifade eder) veya $\mathrm{TS} \leq 2,5 \mathrm{~ms} / \mathrm{atım}$ olması anormal olarak kabul edildi ${ }^{15-18 .}$

\section{İstatistiksel Analiz}

İstatistiksel analiz, Statistical Package for Social Sciences (SPSS Inc., Chicago, IL, ABD), windows için sürüm 20.0 yazılımı kullanılarak yapıldı. Tanımlayıcı istatistikler yapıldı ve tüm veriler ortalama +/- standart sapma veya median (çeyrek1-çeyrek3) olarak ifade edildi. Kategorik değişkenler ise sayı ve yüzde (\%) olarak belirtildi. İki grup arasındaki sayısal değerler normal dağılım gösterip göstermemesine göre Student t-testi veya Mann Whitney $U$ test kullanılarak, kategorik değișkenler ise $\chi 2$ veya Fischer exact testi kullanılarak karşılaştırıldı. Normal dağılan 2 sayısal değişken arasında Pearson korelasyon analizi yapilırken normal dağılmayan sayısal değişkenler arasında Spearman korelayon analizi yapılmıştır. Ardından multilineer regresyon analizi ile değişkenler arasındaki ilişki test edilmiştir. P değeri $<0.05$ olması istatistiksel olarak anlamlı kabul edildi.

\section{BULGULAR VE SONUÇLAR}

Bu çalışmada, 1550 hastadan 100'ünde (6.4\%) egzersizin iyileşme döneminde ventriküler ektopi vardı. 100 hastadan 25'inde (\%25) hem egzersiz hem de egzersizden hemen sonra toparlanma sırasında sık ventriküler ektopi izlendi. Hastaların demografik özellikleri ve efor testi bulguları Tablo I'de sunuldu. Hastaların ortalama yaşı $51.8 \pm 11.2$ yıldı. Hastaların egzersiz sonrası 1. dakikadaki HRR 29.23 (5-65) atım/dakika olarak izlendi ve hastaların \%10'unda, egzersiz sonrası 1. dakika HRR $\leq 12$ atım/dk olup azalmış olarak saptandı. Egzersiz sonrası bir ventriküler ektopi sonrası kalp hızı TO $-0.2(-10-7.3) \%$, TS ise $9.24(0-60) \mathrm{ms} / \mathrm{RR}$ olarak ölçüldü. Egzersiz sonrası kalp hızı TO, hastaların \%35'inde anormal olarak saptanırken, kalp hızı TS hastaların \%17'sinde anormal olarak saptandı (Tablo I). Hastaların yüzde on ikisinde (12\%), elektrokardiyografik ST-segment değişiklikleri ve anjina varlığına göre efor testi sonucu pozitif olarak saptandı ve koroner anjiografi veya iskemi araştırılmak ve risk değerlendirilmesi yapmak üzere ileri tetkik edildi.

Tablo I: Çalışma hastalarının özellikleri ve efor testi bulguları

\begin{tabular}{|c|c|}
\hline Özellikler & Değerler \\
\hline Yaș, yıl & $51.8 \pm 11.2$ \\
\hline $\begin{array}{l}\text { Egzersiz ile maksimum METs } \\
\text { (fonksiyonel kapasite) }\end{array}$ & $9.36(4.6-14.9)$ \\
\hline Efor testi egzersiz süresi, dakika & $\begin{array}{l}7.85(3.15- \\
14.30)\end{array}$ \\
\hline Efor testi pozitif/negatif & $12 / 88$ \\
\hline ST segment çökme miktarı (mm) & $0.34(0-3)$ \\
\hline $\begin{array}{l}\text { Egzersiz sonrası kalp hızı türbülans başlangıcı (T0), } \\
\%\end{array}$ & $-0.2(-10-7.3)$ \\
\hline $\begin{array}{l}\text { Egzersiz sonrası kalp hızı türbülans eğimi (TS), } \\
\text { ms/RR }\end{array}$ & $9.24(0-60)$ \\
\hline $\begin{array}{l}\text { Egzersiz sonrası kalp hızı türbülans başlangıcı (T0), } \\
\text { normal/anormal }\end{array}$ & $65 / 35$ \\
\hline $\begin{array}{l}\text { Egzersiz sonrası kalp hızı türbülans eğimi (TS), } \\
\text { normal/ anormal }\end{array}$ & $83 / 17$ \\
\hline Kalp hızı toparlanma indeksi (HRR), atım/dk & $29.23(5-65)$ \\
\hline HRR normal/anormal & $90 / 10$ \\
\hline Egzersiz sırasındaki ventriküler ektopi (PVC) sayısı & $11.05(0-186)$ \\
\hline $\begin{array}{llr}\text { Egzersiz sonrası toparlanma } & \text { dönemindeki } \\
\text { ventriküler ektopi }(\mathrm{PVC}) \text { sayısı } & \end{array}$ & $3.45(1-29)$ \\
\hline Maksimum ulașılan kalp hızı, atım/dk & $149.57 \pm 17.4$ \\
\hline Bazal kalp hızı, atım/dk & $88.82 \pm 14.45$ \\
\hline
\end{tabular}

Hastalar egzersiz testi sonucuna göre gruplandırıldığında (negatif ve pozitif olarak); yaş, maksimum METs, egzersiz süresi, egzersiz sonrası TO ve TS, TS normal/anormal olanların 
oranı, HRR, HRR normal/anormal oranları, efor testinde egzersiz sırasında PVC sayısı, egzersiz sonrası toparlanma dönemindeki PVC sayısı, maksimum ulaşılan kalp hızı ve bazal kalp hızı açısından iki grup arasında farklılık izlenmedi
(Tablo II). Ancak, TO normal/anormal olanların oranı istatistiksel olarak anlamlı olmasa da efor testi negatif olanlarda daha yüksek olma eğilimindeydi, yani efor testi pozitif olanlarda TO anormal olma eğilimindeydi $(\mathrm{p}=0.07)$.

Tablo II: Efor testi pozitif ve negatif (ST-segmentinde çökme olup olmamasına göre) olan hastaların bulguları

\begin{tabular}{|c|c|c|c|}
\hline Özellikler & $\begin{array}{l}\text { Efor testi pozitif } \\
\qquad(\mathrm{n}=12)\end{array}$ & $\begin{array}{l}\text { Efor testi negatif } \\
\qquad(\mathrm{n}=88)\end{array}$ & p değeri \\
\hline Yaş & $52.66 \pm 13.06$ & $51.69 \pm 11.0$ & 0.77 \\
\hline Diabetes Mellitus,n (\%) & $3(25)$ & $16(18.2)$ & 0.47 \\
\hline Egzersiz ile maksimum METs & $9.43(4.6-13.4)$ & $9.35(4.6-14.9)$ & 0.96 \\
\hline ST segment çökme miktarı (mm) & $1.30(0-3)$ & $0.21(0-1)$ & $<0.001$ \\
\hline Kalp hızı türbülans başlangıcı (TO), \% & $0(-6-7.3)$ & $-0.22(-10-5)$ & 0.38 \\
\hline Kalp hızı türbülans eğimi (TS), ms/RR & $10.1(0-23.3)$ & $9.12(0-60)$ & 0.52 \\
\hline Kalp hızı türbülans başlangıcı (TO), normal/anormal & $7 / 5$ & $58 / 30$ & 0.07 \\
\hline Egzersiz sırasındaki ventriküler ektopi (PVC) sayısı & $11.16(0-76)$ & $11.03(0-186)$ & 0.37 \\
\hline $\begin{array}{l}\text { Egzersiz sonrası toparlanma dönemindeki ventriküler } \\
\text { ektopi (PVC) sayısı }\end{array}$ & $3.75(1-20)$ & $3.4(1-29)$ & 0.89 \\
\hline Maksimum ulaşılan kalp hızı & $146.58 \pm 19.10$ & $149.97 \pm 17.24$ & 0.52 \\
\hline Bazal kalp hızı & $86.25 \pm 11.95$ & $89.17 \pm 14.78$ & 0.51 \\
\hline
\end{tabular}

HRR'nin diğer egzersiz testi parametreleriyle korelasyon analizinde HRR ile kalp hızı TS arasında düşük derecede anlamlı korelasyon izlendi ( $\mathrm{r}=0.21 \mathrm{p}=0.036)$. HRR'nin yaş, egzersiz süresi, maksimum METs, ST-segment depresyonu, TO, egzersiz ve hemen ardından toparlanma sürecindeki PVC sayısı ile korele olmadığı izlendi (Tablo III). Ancak egzersizden hemen sonra toparlanma dönemindeki PVC sayısı ile egzersiz sırasındaki PVC sayısının korele olduğu izlendi $\left(r^{2}=0.34 p<0.001\right)$. Diğer bir korelasyon analizinde ise kalp hızı TS ile TO $\left(r^{2}=0.11\right.$ (negatif) $\left.p=0.001\right)$, ve HRR $\left(r^{2}=0.044\right.$, $\mathrm{p}=0.036$ ) arasinda istatistiksel olarak anlaml korelasyon izlendi. Multilineer regresyon analizinde TS sadece TO ile ilişkili saptandı $(\beta=$ $-0.310 \mathrm{p}=0.019$ ) (Tablo IV). Multilineer regresyon analizinde HRR'nin hiçbir değişkenle ilişkili olmadığı bulundu.

Tablo III: Kalp hızı toparlanma indeksi ile diğer efor testi parametreleri arasındaki korelasyon analizi

\begin{tabular}{|l|l|l|}
\hline Değişkenler & $\begin{array}{l}\text { R korelasyon } \\
\text { katsayısı }\end{array}$ & P değeri \\
\hline Yaş & 0.0001 & 0.998 \\
\hline Efor testi egzersiz süresi & -0.068 & 0.499 \\
\hline Egzersiz ile maksimum METs & -0.044 & 0.664 \\
\hline Efor testi ST-segment depresyonu & 0.082 & 0.417 \\
\hline Kalp hızı türbülans eğimi (TS) & 0.21 & 0.036 \\
\hline Kalp hızı türbülans başlangıcı (TO) & -0.154 & 0.125 \\
\hline $\begin{array}{l}\text { Egzersiz sırasındaki ventriküler ektopi } \\
\text { (PVC) sayısı }\end{array}$ & -0.076 & 0.451 \\
\hline $\begin{array}{l}\text { Egzersiz sonrası toparlanma dönemindeki } \\
\text { ventriküler ektopi (PVC) sayısı }\end{array}$ & 0.137 & 0.173 \\
\hline
\end{tabular}


Tablo IV: Multilineer regresyon analizinde egzersiz sonrası kalp hızı türbülans eğimi (TS) ile diğer değişkenler arasındaki ilişki

\begin{tabular}{|l|l|l|}
\hline Değişkenler & $\begin{array}{l}\text { BETA } \\
\text { değeri }\end{array}$ & P değeri \\
\hline Kalp hızı türbülans başlangıcı (TO) & -0.310 & 0.019 \\
\hline $\begin{array}{l}\text { Kalp hızı türbülans başlangıcı (TO) } \\
\text { normal/anormal }\end{array}$ & -0.022 & 0.867 \\
\hline Kalp hızı toparlanma indeksi (HRR), atım/dk & 0.183 & 0.055 \\
\hline
\end{tabular}

TARTIŞMA

Kardiyovasküler

hastalığın

erken

belirtilerinden

biri kalbin

otonom

dengesizliğidir. Bu çalışmada düşük- orta riskli bireylerde, TO'in hastaların \%35'inde, TS $\% 17$ 'sinde ve HRR ise \%10'unda anormal olup, en erken TO'in bozulmuş olduğunu farkettik. Önceki çalışmalar, otonomik dengedeki anormalliklerin tanımlanmasının, yüksek ölüm riski taşıyan hastaların erken belirlenmesine katkı sağlayabileceğini belirtmektedir ${ }^{1-18}$. Egzersiz boyunca ve egzersiz sonrası dinlenme dönemindeki anormal/yetersiz kalp hızı tepkileri, otonom sinir sistemi disfonksiyonunu ya da kalp gibi end-organların otonom sinir sistemi uyarılarına yeterli yanıt verememesi ile ortaya çıkar ${ }^{4}$. Bu çalışmada, efor testi sırasında iskemik ST-segment değişikliği olan ve olmayanlarda HRR ve HRT parametreleri benzer olarak izlendi. Egzersiz sonrası toparlanma dönemindeki PVC sayısı ile egzersiz sırasındaki PVC sayısı koreleyken HRR ve HRT parametreleri ile PVC sıklığı arasında bir ilişki yoktu. Ayrıca, HRR ile kalp hızı TS arasında düşük derecede anlamlı bir korelasyon vardı. $\mathrm{Bu}$ çalışmada düşük-orta riskli bireylerde, bozulmuş vagal aktivasyon ile ilişkili bu iki parametrenin otonom sinir sistemi dengesizliğinin farklı yönlerini yansıtıyor olabileceğini, iskemi ve PVC sıklığından bağımsız olduğunu gördük.

HRR'nin prognostik değeri net olarak bilinse de $\mathrm{KAH}$ varlığı ve yaygınlığı, miyokard sintigrafisindeki perfüzyon defektleri, efor testinde ST-segment değişiklikleri ve Duke treadmill skoru ile ilişkisi hakkında literatürde farklı sonuçlar vardır. Egzersiz sonrası 1. ve 2. dakikadaki azalmış HRR'nin KAH varlığı ile ilişkili olduğu gösterilmiştir' ${ }^{19,20}$. Jae ve arkadaşları ise 2. dakikadaki HRR <38 atım olanlarda yaygın koroner arter kalsifikasyonunun daha sı olduğunu belirtmiștir ${ }^{21}$. Lipinski ve arkadaşları, KAH olan kişilerin 2., 3. ve 5. dakikada daha düşük HRR'ye sahip olduklarını fakat 1. dakikadaki HRR'nin $\mathrm{KAH}$ varlığından etkilenmediğini belirtmiştir. Özellikle de 2. dakika süresince olan kalp hızı düşüşünün KAH varlığı ile ilişkili olduğunu göstermişlerdir (KH1.dakika-KH2.dakika) ${ }^{12}$. Buna karşın Shetler ve arkadaşları, 2. dakikadaki anormal kalp hızı düșüșünün $(<22$ atım) KAH ciddiyetinden bağımsız olarak mortaliteyi öngördügünü ancak KAH varlığı ile ilişkili olmadığını göstermiştir ${ }^{11}$. Ghaffari ve arkadaşları da egzersiz sonrası 1. dakikada oturur pozisyonda HRR'nin $\leq 18$ atım/dk olmasının KAH ciddiyeti ile ilişkili olduğunu ancak KAH varlığını öngörmediğini belirtmişlerdir ${ }^{22}$. Farkedildiği gibi bu çalışmalarda farklı protokoller, farklı ölçüm metodları ve farklı referans değerleri kullanılmıştır, bu da çalışmalar arasında uyumsuz sonuçlara neden olmuş olabilir. Egzersizden hemen sonra yatar pozisyona geçilmesi önerilmesine rağmen, egzersiz sonrası toparlanma döneminde hastanın oturur pozisyonda veya ayakta olması, soğuma yürüyüşü yapılıp yapılmaması, ve hastanın fiziksel durumuna ve yaşına göre supin pozisyona geçme sürecindeki farklılıklar egzersiz sonrası 1. dakikadaki HRR'yi ve onun duyarlılığını etkilediği düşünülmektedir. Vivekananthan ve arkadaşları yine egzersiz sonrası 1. dakikada anormal HRR'si olan hastaların yaygın KAH'na sahip olma olasılıklarının yüksek olduğunu ancak anjiografik olarak KAH varlığını belirlemek için zayıf bir test olduğunu vurgulamışlardır 
(duyarlılık \%31, özgüllük \%76) ${ }^{14}$. Ayrıca bu çalışmada ilginç şekilde HRR'si düşük olanlarda anormal ST-segment değişikliğinin daha az olduğunu görmüşlerdir ${ }^{14}$. Bizim çalışmamızda rölatif olarak düşük riskli hastaların olması ve egzersiz sonrası 1 . dakikadaki HRR'nin değerlendirilmesi onun ST-segment değişikliği veya PVC sıklığı ile ilişkisinin gösterilememiş olmasına neden olmuş olabilir. Shetler ve Lipinski'nin çalışmalarında da belirtildiği gibi 2 . dakikadaki HRR kardiyovasküler olayları öngörmede daha iyi bir performans sergileyebilir ${ }^{11,12}$.

Bunların dışında iskemi ile HRR ilişkisi yine dikkat çeken bir konu olmuştur. Georgoulias ve arkadaşlarının yaptığı çalışmada egzersiz sonrası 1. dakikadaki anormal HRR'nin ( $\leq 21 \mathrm{atım} / \mathrm{dk}$ ) stress miyokard perfüzyon skoru ile korele olduğu ve bu hastalarda egzersiz sırasında anjina ve ST-segment değișikliğinin daha sık olduğu gösterilmiştir ${ }^{23}$. Nishime ve arkadaşlarının yaptığı çalışmada egzersiz sonrası soğuma yürüyüşü sırasında 1 . dakikadaki anormal HRR'nin ve orta-yüksek Duke skorunun ölümü öngördüğü ancak HRR normal ve anormal olanlar arasında ST-segment depresyonu, ST-segment değişikliği yorumunun benzer olduğu gösterilmiştir ${ }^{10}$. Naghedi ve arkadaşlarının yaptığı çalışmada 1 . ve 2 . dakikadaki HRR ile miyokardiyal perfüzyon görüntüleme bulguları arasında bir ilişki saptanamamıştır ${ }^{24}$. Ayrıca, Lima ve arkadaşları egzersiz sonrası 1. dakikada soğuma yürüyüşü sırasındaki anormal HRR'nin düşük sol ventrikül ejeksiyon fraksiyonu, istirahat perfüzyon defektinin ciddiyeti ve yaygınlığı ile ilişkili olduğunu ancak miyokardiyal iskemi ile ilişkili olmadığını yayınlamışlardır. Yazarlar, HRR patofizyolojisinde miyokardiyal skarın ya da miyokard disfonksiyonunun iskemiden daha önemli olabileceğini bildirmiştir ${ }^{25}$. Georgoulias ve arkadaşlarının yaptığı çalışmada daha önceden miyokard enfarktüsü geçirmiş olan veya skarı olan hastaları çalışmaya almadıkları için sonucun etkilenmiş olabileceği şeklinde yorumlanmıştır. Benzer şekilde Desai ve arkadaşlarının yaptığı çalışmada egzersiz sonrası 1. dakika HRR'si normal veya anormal ( $\leq 12 \mathrm{atım} / \mathrm{dk}$ ) olanlarda iskemi sıklığı benzer olsa da anormal HRR grubunda daha fazla düşük sol ventrikül ejeksiyon fraksiyonu $(<50 \%)$ olan hasta mevcuttu (56\% vs $24 \%)^{26}$. Bizim çalışmamızda kalp yetmezliği olan hastalar dışlanmış ve daha önceden bilinen KAH olmayan düşük -orta riskli hastalar dahil edildiğinden, HRR ile hiçbir değişken ilişkili bulunmamıș olabilir.

HRT, bir PVC'ye yanıt olarak sinüs ritminin hızlanması ve ardından yavaşlaması ile fizyolojik, iki fazlı bir reaksiyondur. HRT'nin ortadan kalkması, normal otonom sinir sistemi regülasyonunun bozulmuş olmasını ifade eder. HRT'nin kardiyak mortalitenin ve ani kardiyak ölümün bir belirleyicisi olduğu gösterilmiştir ${ }^{15-}$ 18,27-29. Miyokard enfarktüsü geçirmiş ve/veya kalp yetmezliği olan hastalarda bozulmuş HRT'nin kardiyak mortalite, tüm nedenlere bağlı mortalite ve ventriküler aritmilerin belirleyicisi olduğu gösterilmiştir ${ }^{17}$. Ancak KAH olanlar ile yapisal olarak normal ancak ventriküler aritmileri olan hastalar karşılaştırıldığında HRT değişkenlerinin yaştan ve sol ventrikül fonksiyonlarından bağımsız olarak stabil KAH olanlarda bozulduğu gösterilmiştir ${ }^{30}$. Bizim çalıșmamızda efor testi pozitif olanlarda TO anormal olma eğiliminde olsa da istatistiksel olarak HRT ile ST-segment değişikliği olması veya PVC sıklığı arasında ilişki gösterilememiştir.

$\mathrm{Bu}$ çalışmanın kısıtlılıkları arasında vaka sayısının az olması; tek merkezli, retrospektif bir çalışma olması mevcuttur. İkincisi, düşük risk veya orta riskin baskınlığı ile gösterildiği gibi, popülasyonumuz genel olarak sağlıklıydı. Bulguların daha fazla hasta sayısının olduğu kapsamlı bir çalışma ile doğrulanmasını ve egzersiz sonrası 1 . ve 2. dakikadaki HRR ile HRT'nin kardiyovasküler olaylar ile ilişkisinin 
prospektif çalışmalarla değerlendirilmesi uygun olabilir.

\section{SONUÇ}

Düşük-orta riskli bireylerde, TO hastaların \%35'inde, TS \%17'sinde ve HRR ise \%10'unda anormal olup, en erken TO bozulmuştur. Bu hastalarda bozulmuş vagal aktivasyon ile ilişkili HRT ve toparlanmanın 1 . dakikasındaki HRR'nin, otonomik disfonksiyonun farklı yönlerini yansitıyor olabilirler ve bunlar, egzersiz testi sırasındaki iskemik ST-segment değişikliği varlığı ve ventriküler ektopi sıklığı ile ilişkili değildi. Ancak, bu bulgular örneklem sayısının azlığı dikkate alınarak yorumlanmalı, daha kapsamlı ve longitudinal çalışmalarda bu parametrelerin birbiri ve aritmik olaylar ile ilişkisi değerlendirilmelidir.

Etik Kurul Kararı: $\mathrm{Bu}$ çalışma, Helsinki bildigesindeki etik yönergeler dikkate alınarak yapılmıştır. Bu çalışma hastanemiz etik kurulu tarafından onaylanmıștır (karar no: 2021/7/502).

Çıkar Çatışması Beyanı: Çıkar çatışması bulunmamaktadır.

Finansal Destek: Bu çalışma her hangi bir fon tarafından desteklenmemiştir.

Declaration of Conflicting Interests: The author declare that she has no conflict of interest.

Financial Disclosure: No financial support was received.

\section{KAYNAKLAR}

1. Elhendy A, Chandrasekaran K, Gersh BJ, et al. Functional and prognostic significance of exerciseinduced ventricular arrhythmias in patients with suspected coronary artery disease. Am J Cardiol. 2002; 90: 95-100.

2. Frolkis JP, Pothier CE, Blackstone EH, Lauer MS. Frequent ventricular ectopy after exercise as a predictor of death. N Engl J Med. 2003; 348: 781-90.
3. Higgins JP, Higgins JA. Electrocardiographic exercise stress testing: An update beyond the ST segment. Int J Cardiol. 2007; 116: 285-99.

4. Ören H, Aytemir K. Kalp Hızı Toparlanma İndeksi: Klinik Kullanım ve Yöntemler. TAPE. 2008; 6: 14150.

5. Cole CR, Blackstone EH, Pashkow FJ, Snader CE, Lauer MS. Heart-rate recovery immediately after exercise as a predictor of mortality. $\mathrm{N}$ Engl J Med. 1999; 341: 1351-7.

6. Qiu S, Cai X, Sun Z, et al. Heart Rate Recovery and Risk of Cardiovascular Events and All-Cause Mortality: A Meta-Analysis of Prospective Cohort Studies. J Am Heart Assoc. 2017; 6: e005505.

7. Sydó N, Sydó T, Gonzalez Carta KA, et al. Prognostic Performance of Heart Rate Recovery on an Exercise Test in a Primary Prevention Population. J Am Heart Assoc. 2018; 7: e008143.

8. Lachman S, Terbraak MS, Limpens J, et al. The prognostic value of heart rate recovery in patients with coronary artery disease: A systematic review and meta-analysis. Am Heart J. 2018; 199: 163-9.

9. Cole CR, Foody JM, Blackstone EH, Lauer MS. Heart rate recovery after submaximal exercise testing as a predictor of mortality in a cardiovascularly healthy cohort. Ann Intern Med. 2000; 132: 552-5.

10. Nishime EO, Cole CR, Blackstone EH, Pashkow FJ, Lauer MS. Heart rate recovery and treadmill exercise score as predictors of mortality in patients referred for exercise ECG. JAMA. 2000; 284: 1392-8.

11. Shetler K, Marcus R, Froelicher VF, et al. Heart rate recovery: validation and methodologic issues. J Am Coll Cardiol. 2001; 38: 1980-7.

12. Lipinski MJ, Vetrovec GW, Froelicher VF. Importance of the first two minutes of heart rate recovery after exercise treadmill testing in predicting mortality and the presence of coronary artery disease in men. Am J Cardiol. 2004; 93: 4459.

13. Diaz LA, Brunken RC, Blackstone EH, Snader CE, Lauer MS. Independent contribution of myocardial perfusion defects to exercise capacity and heart rate recovery for prediction of all-cause mortality in patients with known or suspected coronary heart disease. J Am Coll Cardiol. 2001; 37: 1558-64. 
14. Vivekananthan DP, Blackstone EH, Pothier CE, Lauer MS. Heart rate recovery after exercise is a predictor of mortality, independent of the angiographic severity of coronary disease. J Am Coll Cardiol. 2003; 42: 831-8.

15. Schmidt G, Malik M, Barthel P, et al. Heart-rate turbulence after ventricular premature beats as a predictor of mortality after acute myocardial infarction. Lancet. 1999; 353(9162): 1390-6.

16. Biçer A, Akdemir R, Karakurt 0, et al. Heart rate variability and turbulence analysis in patients with psoriasis. Dicle Med J. 2010; 37: 326-31.

17. Disertori M, Masè M, Rigoni M, Nollo G, Ravelli F. Heart Rate Turbulence Is a Powerful Predictor of Cardiac Death and Ventricular Arrhythmias in Postmyocardial Infarction and Heart Failure Patients: A Systematic Review and Meta-Analysis. Circ Arrhythm Electrophysiol. 2016; 9: e004610.

18. Francis J, Watanabe MA, Schmidt G. Heart rate turbulence: a new predictor for risk of sudden cardiac death. Ann Noninvasive Electrocardiol. 2005; 10: 102-9.

19. Tan YZ, Özdemir S, Altun B, Çelik F. Assessment of Heart Rate Recovery with GATED-Myocardial Perfusion Scintigraphy Outcome in Patients with Coronary Artery Disease: A Retrospective Study and Institutional Experience. Mol Imaging Radionucl Ther. 2016; 25: 121-7.

20. Akyüz A, Alpsoy S, Akkoyun DC, Değirmenci H, Güler N. Heart rate recovery may predict the presence of coronary artery disease. Anadolu Kardiyol Derg. 2014; 14: 351-6.

21. Jae SY, Kurl S, Laukkanen JA, et al. Relation of heart rate recovery after exercise testing to coronary artery calcification. Ann Med. 2017; 49: 404-10.

22. Ghaffari S, Kazemi B, Aliakbarzadeh P. Abnormal heart rate recovery after exercise predicts coronary artery disease severity. Cardiol J. 2011; 18: 47-54.
23. Georgoulias P, Orfanakis A, Demakopoulos N, et al. Abnormal heart rate recovery immediately after treadmill testing: correlation with clinical, exercise testing, and myocardial perfusion parameters. J Nucl Cardiol. 2003; 10: 498-505.

24. Naghedi A, Namiranian N, Goudarzi M, Moghadam RN, Razavi-Ratki SK. Could heart rate recovery and exercise capacity predict abnormal 99mTc-MIBI myocardial perfusion scan findings? Glob Cardiol Sci Pract. 2021; 2021: e202107.

25. Lima RS, De Lorenzo A, Soares AJ. Relation between postexercise abnormal heart rate recovery and myocardial damage evidenced by gated singlephoton emission computed tomography. Am J Cardiol. 2006; 97: 1452-4.

26. Desai MY, De La Peña-Almaguer E, Mannting F. Abnormal heart rate recovery after exercise: a comparison with known indicators of increased mortality. Cardiology. 2001; 96: 38-44.

27. Sredniawa B, Cebula S, Kowalczyk J, et al. Heart rate turbulence for prediction of heart transplantation and mortality in chronic heart failure. Ann Noninvasive Electrocardiol. 2010; 15: 230-7.

28. Stein PK, Deedwania P. Usefulness of abnormal heart rate turbulence to predict cardiovascular mortality in high-risk patients with acute myocardial infarction and left ventricular dysfunction (from the EPHESUS study). Am J Cardiol. 2009; 103: 1495-9.

29. Huikuri HV, Exner DV, Kavanagh KM, et al.; CARISMA and REFINE Investigators. Attenuated recovery of heart rate turbulence early after myocardial infarction identifies patients at high risk for fatal or near-fatal arrhythmic events. Heart Rhythm. 2010; 7: 229-35.

30. Sestito A, Valsecchi S, Infusino F, et al. Differences in heart rate turbulence between patients with coronary artery disease and patients with ventricular arrhythmias but structurally normal hearts. Am J Cardiol. 2004; 93: 1114-8. 